\author{
James A Athanasou \\ University of Sydney, Faculty of Health Sciences, \\ Australia \\ Dates: Received: 23 July, 2015; Accepted: 19 \\ August, 2015; Published: 20 August, 2015 \\ *Corresponding author: James A Athanasou, \\ Faculty of Health Sciences, University of Sydney, \\ Australia, Tel: +61 2 9351-9329; E-mail: james. \\ athanasou@sydney.edu.au \\ www.peertechz.com
}

ISSN: 2455-3484

Keywords: Pre-accident adjustment; Post-accident adjustment; Compensable injury; Addiction

\author{
Case Report
}

\section{The Effects of Substance Abuse Following Personal Injury: Five Case Studies from a Medico-Legal Context}

\section{Introduction}

The focus of this paper is on the vocational, educational and psychosocial consequences of dependence or pathological overuse of a drug in relation to a personal injury. The clinically significant impairment or distress accompanying addiction [1], together with the neurobiological features of drug reward [2] are already welldocumented. There has been a concern for medication use and its effects in relation to injury [3]. For instance, dependence on pharmacological control of pain has been mentioned in relation to burn injuries [4] The substance abuse of patients with compensable injuries, however, has been documented but only sporadically since the early 1990s [5] and almost exclusively in relation to spinal cord injury or traumatic brain injury. Indeed, Bombardier and Turner [6] used traumatic brain injury and spinal cord injury as explicit "examples of disabling conditions in which alcohol- or drug-related problems play a significant role" (p. 241) whereas musculoskeletal injuries are 33 times more frequent than head injury in an Australian context [7].

The picture that has emerged is one of quite varied substance abuse influenced by both pre- and post-accident factors. The prevalence of alcohol abuse is just over one-fifth for patients with a spinal cord injury in community care. On the other hand, excessive alcohol use has been reported to continue following traumatic brain injury [8]. Miller et al. [9] reported increased dependence and abuse following mild traumatic brain injury in active duty US airmen.

This paper provides a clinical report of five case studies from a service that focuses on personal injury. The five most recent cases that involved substance abuse are described in terms of their effects. These are characterised in terms of interpersonal, work, family or school problems. The cases were not specially selected but are notable for including post-traumatic stress disorder, medical negligence, traumatic brain injury and musculoskeletal injuries. No claim is made that these cases are representative. They involve both pre- and post-accident addictions and substance abuse in order to sketch out the parameters of a theoretical approach to rehabilitation practice. Each case study includes relevant background details.

\section{Case Study A - Post-traumatic stress and post- accident heavy drinking}

Mrs A is a 32-year old female who was affected by a work-related incident that led to post-traumatic stress. She suffers from anxiety, severe depression, lethargy, nausea and a phobia of public places.

Education: She completed her schooling to Year 10 level. Her reading standard is at senior high school level. She has completed a variety of technical college courses in welfare. She had not been referred for rehabilitation assistance.

Work: Her employment history centered on a range of peoplecontact activities. She was employed as a permanent part-time welfare worker in a community health unit.

Social: She is married and lives in her own home with her husband and three sons. There have been problems in personal adjustment including a suicide attempt. She indicated that she has become a heavy daily drinker. She has not been admitted to a psychiatric ward.

On the Eysenck Personality Questionnaire [10] she indicated significantly elevated levels of responses on the neuroticism, lie and addiction scales. These results are summarized in the below.

\begin{tabular}{|c|c|c|c|}
\hline Category & $\begin{array}{l}\text { Her } \\
\text { score }\end{array}$ & $\begin{array}{l}\text { Average for } \\
\text { females } 31-40 \\
\text { years }\end{array}$ & $\begin{array}{l}\text { Maximum } \\
\text { possible } \\
\text { score }\end{array}$ \\
\hline $\begin{array}{l}\text { Psychoticism } \\
\text { Extraversion } \\
\text { Neuroticism } \\
\text { Lie scale } \\
\text { Addiction }\end{array}$ & $\begin{array}{l}8 \\
7 \\
24 \\
15 \\
22\end{array}$ & $\begin{array}{l}6 \\
14 \\
12 \\
7 \\
13 \text { (normals) } \\
20 \text { (addicts) }\end{array}$ & $\begin{array}{l}32 \\
23 \\
24 \\
21 \\
32\end{array}$ \\
\hline
\end{tabular}


These results are complex. Such a high score in neuroticism is rare. There may be a degree of overemphasis or exaggeration of symptoms but at the same time there are significant issues of adjustment that need professional attention. This was a case in which problems occurred following an injury and it highlights the complex interaction between person, context, injury and substance use.

The next case study indicates a scenario that will be encountered quite frequently in dealing with injury. In this instance alcohol use was a problem prior to an injury and continued following the injury.

\section{Case study B - Medical negligence and pre-accident heavy drinking}

$\mathrm{Mr} \mathrm{B}$ is a 49-year-old male, who alleged medical negligence during the course of medical treatment. This arose from a failure to diagnose a leg infection. On specific questioning, he indicated that the special difficulties he has in working now were: "painful to walk around and stand... extremely difficult to work in a full-time job when putting weight on my feet".

Education: He completed his schooling to Year 10 level. His reading standard was around senior high school level. He is qualified as a formwork carpenter.

Work: He has worked mainly in hospitality and catering but at the time of the incident, he was employed as a formwork carpenter. He had been employed in that job for only 4-5 months. He had returned to work after a prolonged absence from the workforce for a period of alcohol rehabilitation. He said that he was satisfied with the job and with the pay. The job was described as stressful, physically and mentally exhausting.

He has worked since this incident. He last worked in customer service two years ago before being admitted to a residential alcohol rehabilitation unit for 2-3 months. Then he enrolled in a long-term residential program for 18 months and graduated from this program less than 2 months ago.

At the present time he receives a social security benefit of around $\$ 500$ per fortnight. He has not looked for work since returning home as he wants to spend some time with his family. He thought that it would be difficult for him to work full-time.

Social: He is married and lives in his own home, with his wife and their three children who are in primary school. He indicated that he never had a nervous breakdown and had never seen a doctor for nerves. He has seen a psychologist for counselling. He never made a suicide attempt and has never been in a psychiatric ward. He does smoke but said that he no longer drinks. He has never taken hard drugs.

His pattern of problem drinking is long-standing. More than five years ago there was a note in the clinical records of his general practitioner relating to treatment for alcohol use. He has been in trouble with the law. He will regain his driving licence in three years. He manages his own finances.

Physical: On tests of manual skills, he indicated reasonable grip strength. On the Jamar dynamometer, his maximum grip on this occasion was $45 \mathrm{~kg}$ in the right hand and $42 \mathrm{~kg}$ in the left hand.
Both values are within normal limits. On the back-leg pull strength dynamometer, he exerted $122 \mathrm{~kg}$ force, which is below average. On the Purdue Pegboard which is a timed test of manual dexterity requiring the rapid placement of small component parts, he placed 15 components with the right hand and 14 components with the left hand (compared with around 16 placements for a small sample of males).

Systems check: The history was coherent, internally consistent and spontaneous. For work purposes his speech was clear and he did not display any word finding or comprehension difficulties. He was able to describe events pertaining to his education and work. His capacity to deal with the affairs of the examination was within normal limits.

On brief office testing of mental status, he was oriented in time, date and place but not day or season. He had trouble recalling the names of political personalities. He was able to interpret a concrete but not abstract proverb. Mental arithmetic calculation and reasoning with similarities were accurate and he was able to make a correct practical judgement in an unfamiliar situation. On the Lezak 15-item test, which is designed to reveal whether a person is giving their best performance, he recalled 12 out of the 15 items. This is an adequate effort. My imprecise observation was that there may be some cognitive difficulties.

Presentation: He presented as a man of stated age and normal build. He was dressed in a casual fashion. He related in a pleasant manner. His behaviour was appropriate to the situation. He presents as someone who seems affected.

In this instance the issue is alcoholism in the context of a person's pre- and post-accident adjustment. It is not a remarkable to statement to indicate that addiction may accompany a range of problems. It may be a consequence or at least occur following an injury. The next example relates to heroin and cocaine use and the subsequent case study involves methadone treatment.

\section{Case study C -Traumatic brain injury and pre- accident heroin and cocaine use}

This case concerns an 11-year old male who was involved in a motor vehicle accident. His disabilities included cognitive deficits, epilepsy and behavioural difficulties.

Education: Master C was repeating Year 5 at the time of the accident. Following the accident he went on to complete his secondary schooling to year 8 level (age 14 years). He has no formal post-school qualifications or training.

Intellectual ability: The results of a formal assessment of his intellectual ability indicate someone of well below average IQ (fullscale IQ=52).

Employment: He has not worked since leaving school.

Social: His family background indicated significant problems of personal and social adjustment. He has now become an intravenous drug user of heroin and cocaine. The initial exposure to these substances was not documented. 
Once again, this vignette indicates that the problem of substance use or abuse is hardly independent of other factors. It does not occur in a vacuum. There are some cases that manifest multiple problems [11]. It is linked to pre-accident factors as well as post-accident adjustment. This theme is also taken up in the next case study.

\section{Case study D - Musculoskeletal injuries, head injury and post-accident methadone program}

Ms D is a 24-year-old female who was injured in a motor vehicle accident. Her injuries included fractured right femur, right humerus, right ankle, fractured right clavicle and a head injury. She has suffered from psychological problems and a psychotic illness with suicidal ideation following the accident.

Education: She completed her schooling to Year 11 level. Her reading standard was around junior high school level. She commenced various courses at technical college but did not complete them. She obtained the Responsible Service of Alcohol and Responsible Conduct of Gaming with the assistance of a rehabilitation provider.

Work: On the Career Interest Card Sort [12] she displayed a major preference for Creative and Office activities and a dislike of Business and Scientific activities. Her pre-accident employment history was characterised by short-term jobs mainly in retail. She had been unemployed for around one year at the time of the accident.

She has worked since the accident. This was in elementary sales and service jobs but only for a maximum of 2-3 months.

Social: She is single. There have been problems of personal adjustment. She has seen counsellors. She had a nervous breakdown. She made suicide attempts. She is a smoker and she drinks. She has never been a heavy drinker. She has taken hard drugs and is on a methadone program. She been convicted twice for assault and was in prison for half a day.

This brief description masks the accumulated social disadvantage that is encountered in some cases. The same context of disadvantage is also illustrated in the following case where addiction is only one of the relevant factors.

\section{Case study E - Musculoskeletal injuries, widespread drug use and criminal behaviour}

Mr E is a 31-year-old male, who was injured in a motor vehicle accident. His injuries left him with a restriction of movement and agility, right knee pain, intermittent pain in the left ankle.

He has a criminal history from age 12 (e.g., disorderly behavior, possession of weapons, break and enter, unlawful use of motor vehicles, stealing, fraud, willful damage, grievous bodily harm, possess stolen property, breach bail, drugs and obstruct police related offences). He spent considerable time in prison. He has a history of drug use (marijuana, ecstasy, amphetamines, and heroin) since the age of 13. In this case the use of drugs preceded the accident. These details were available from police records and corrective services.

Education: He was expelled in junior high school.

Work: Whilst in custody he worked in agriculture and laundry jobs. He had never worked in paid employment since leaving school.

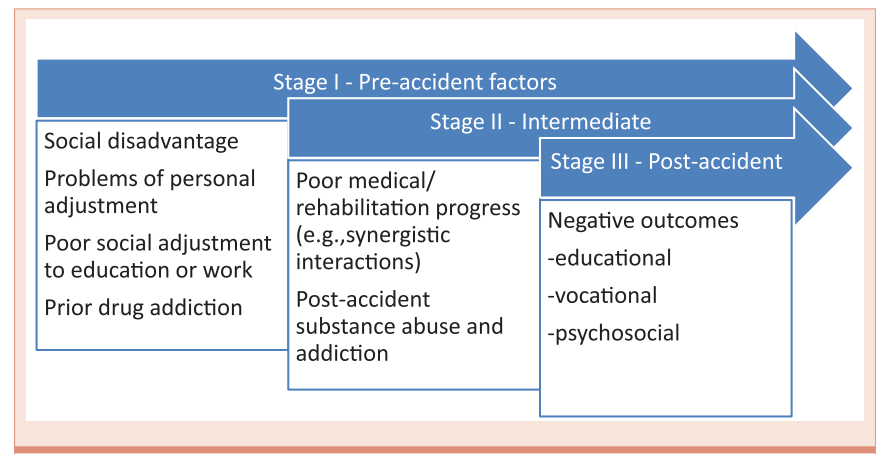

Figure 1: Hypothesised model linking addiction to outcomes of personal injury.

He has never been in the community for more than 9 months. He has not worked since the accident. He is currently incarcerated.

There were few, if any, prospects of securing paid employment. A rehabilitation report listed ten barriers to work. These factors included: drug dependence; accommodation; ex-offender history; anxiety levels; confidence; formal education; limited employment history; job seeking skills; transport; and the need for workplace support.

\section{Concluding Comments}

These case studies describe heterogeneous circumstances associated with substance abuse. They indicate that addiction and substance abuse are not clear-cut issues in personal injury matters. They operate across a wide variety of disabilities. Nevertheless, in each instance there were negative vocational, educational and psychosocial outcomes that were exacerbated by addiction.

The vignettes are not defined in terms of psychiatric diagnosis but instead highlight the impact that substance abuse disorder wreaks on people's lives. At present there is no clear answer in terms of theorising about the role of addiction and substance abuse. There are clear synergies between past and present circumstances. At best, one may predict the potential for problems from prior substance abuse. Pre-accident personal adjustment is also a factor in substance abuse as is social disadvantage.

Figure 1 provides a schematic for the hypothesised processes that occur prior to a personal injury as well as following the injury. The pre-accident factors - especially the extent of pre-accident addiction - provide the foundation for adjustment to trauma and disability. The pre-accident factors combine with treatment and rehabilitation processes to predict the likelihood of negative outcomes across educational, vocational and psychosocial domains. It is argued that addiction is linked not only to traumatic spinal cord and traumatic head injury but operates across the entire spectrum of disability. There does not appear to be any quick-fix for these issues and by all accounts it will require considerable case management time.

\section{Acknowledgment}

An earlier version of this paper was presented at the 2015 Aspects of Psychosocial and Medical Rehabilitation annual lecture, The University of Sydney, Lidcombe. 


\section{References}

1. Camf J, Farre M (2003) Drug addiction. New Engl J Med 349: 975-986.

2. Adinoff $B$ (2004) Neurobiologic processes in drug reward and addiction. Harv Rev Psychiat 12: 305-320.

3. Talmage JB, Melhorn JM (2005) A physician's guide to return to work Chicago III: American Medical Association Press.

4. Askay SW, Patterson D (2010) Psychological rehabilitation in burn injuries In RG Frank M Rosenthal, B Caplan (Eds) Handbook of rehabilitation psychology 2nd ed pp 107-118 Washington DC: American Psychological Association.

5. Greer BG, Roberts R, Jenkins WM (1990) Substance abuse amongs clients with other primary disabilities: Curricular implications for rehabilitation education. Rehabil Educ 4 33-44.

6. Bombardier $\mathrm{CH}$, Turner AP (2010) Alcohol and other drug use in traumatic disability In RG Frank M Rosenthal, B Caplan (Eds) Handbook of rehabilitation psychology 2nd ed pp 241-254 Washington DC: American Psychological Association.
7. Australian Bureau of Statistics (2013) Disability, Ageing and Carers, Australia Catalogue No 4430.0 November 2013 Canberra: Author.

8. Bogner JA, Corrigan JD, Mysiw WJ, Clinchot D, Fugate L (2001) A comparison of substance abuse and violence in the prediction of long-term rehabilitation outcomes after traumatic brain injury. Arch Phys Med Rehab 82 571-577.

9. Miller SC, Baktash SH, Webb TS, Whitehead CR, Maynard C, et al. (2013) Risk for addiction-related disorders following mild traumatic brain injury in a large cohort of active-duty U.S. airmen. Am J Psychiat 170 383-390.

10. Eysenck HJ, Eysenck SBG (1975) Manual of the Eysenck Personality Questionnaire (adult and junior) London: Hodder, Stoughton.

11. American Academy of Pediatrics (2000) Indications for management and referral of patients involved in substance abuse. Pediatrics 106: 143-148.

12. Athanasou JA, Hosking K (2015) Career interest card sort for vocational assessment and counselling In M McMahon , W Patton (Eds) Ideas for career practitioners Celebrating excellence in career practice pp 1-10 Stanford Valley Qld: Australian Academic Press. 